\title{
A Methodological Framework for Analysing the Social Costs of Adjustment at the Micro-level: the Case of Guayaquil, Ecuador ${ }^{1}$
}

\section{Peter Sollis and Caroline Moser}

\section{Introduction}

The purpose of this paper is to describe a recently developed research methodology to examine the social dimensions of debt, recession and structural adjustment policies (SAP) in terms of their impact on low income urban households. The paper draws on the specific experience of a research project that included six weeks's fieldwork, undertaken during the summer of 1988 in the suburbios, or low income urban areas, of Guayaquil, Ecuador. Since the nature and type of information collected during fieldwork ultimately determines the type and extent of analysis that can be undertaken, the choice of research methodology in social development research is critical. This is a complex question which must take into account such issues as the nature of the research problem, the context of the research, the amount of accessible secondary and background data, and the time available in the field.

\section{The Research Problem}

Until recently, research on the impact of SAP has focused mainly at the macro-economic level with few sociological or anthrological studies looking at the social dimensions of SAP. It is now widely recognised that the debt crisis and recession experienced over the past decade in many Third World countries, with the resulting stabilisation and structural adjustment policies, have had different implications for various social and economic groups in both rural and urban areas. Criticisms have been voiced that the social costs of SAP have been most heavily borne by low-income populations, resulting in a severe erosion of the human resources base of the economy. These have led to proposals to modify the adjustment process to include a 'Human Face' [Cornea et al. 1987; 1988], with policies 'to strengthen the human resource base' [Demery and Addison 1987].

It has also been recognised that within households SAPs often have had a differential impact on men and women because of the gender bias in macro-economic

\footnotetext{
${ }^{1}$ An earlier version of this paper was presented at the Workshop on Evaluation of Social Development held at the Centre for Development Studies, University College of Swansea, September 1989. The authors would like to thank Roslind Eyben, Sean Conlin and Mick Howes for their comments.
}

policy formulated to reallocate resources [Elson 1987]. This assumes implicity that the process of reproduction and maintenance of human resources, which is carried out unpaid by women, will continue regardless of the way in which resources are reallocated. It further assumes that changes in income, food prices and public expenditure accompanying SAP and stabilisation affect all members of the household in the same way because of equal intrahousehold resource distribution.

Such assumptions have generated concern on two accounts: firstly, that adjustment policies are only achieved at the cost of longer and harder working hours for women, who are forced to increase their labour both within the market and the household; secondly, that women's labour is not infinitely elastic - a breaking point may be reached and women's capacity to reproduce and maintain human resources may collapse [Elson 1987]. However, for such concern to be widely confirmed and translated into policy recommendations, far greater evidence is still required as to how the position of women has changed during the adjustment period within specific contexts, and, through the identification of causality, the degree to which these changes have been linked to particular adjustment policies.

In order to contribute to this policy debate a research project was initiated by the authors, the purpose of which was to examine the social costs of adjustment for poor urban households in terms of four important changes; changes in household consumption patterns; changes in household employment; the intrahousehold impact of changes in sectoral spending in health and education; and changes in the balance between women's time in their productive, reproductive and community managing roles [Moser 1989]. Clarification and identification of these very specific research objectives from secondary sources and consultation was identified as an essential precondition for the success of time constrained research, since the research problem determines both the choice of research location and the design of the research methodology.

\section{Evaluation of Alternative Research Methodologies}

Once the research problem was clearly identified, the 
next major consideration was the selection of the most appropriate research methology. From the literature available three different approaches were identified as potentially useful. The first is an NGO campaigning approach whose purpose is to make policy makers rethink their assumptions. This is exemplified by the work of John Clark at Oxfam on debt and poverty in Zambia [Clark 1987; 1988]. He seeks to establish the causal links between increasing poverty and SAP, through the building up of comparative evidence from a number of sources such as individual 'key' informants, interviews with academics and political authorities, the use of secondary data and the experience of poverty focused development projects with grassroots groups.

However, the major shortcoming in Clark's work is the way data has been collected. For example, in the case of the "key" informants who provided case example material there is no indication as to the criteria used for their selection. The available evidence suggests that they were chosen in an arbitrary manner rather than one based on scientific random selection procedures, with circumstance playing a greater role than systematic selection techniques. This means there is no framework to indicate how representative the experiences of the key informants are. Therefore it allows unsympathetic listeners to dismiss such work as non-rigorous and unrepresentative. Heavy emphasis is placed on the use of inference, which rests on a series of unsubstantiated assumptions, to imply that because adjustment measures have affected one or two people in a particular way, the same holds true for a vast majority of the poor.

In the absence of a research methodology that can identify the strategies followed by low-income populations in the face of increasing poverty, what tends to emerge is a two dimensional, sensationalised picture of how people respond to economic crisis. Since the limited number of life histories cannot be related to ongoing processes of impoverishment or provide for direct inference to a population, the life histories remain at the anecdotal, individualistic level of 'apt illustration' [Gluckman 1958]. This approach makes limited use of the access to communities and households that local and national NGOs, through their development and emergency work, can provide. Instead of taking advantage of this opportunity to develop a broader understanding of the social dimensions of adjustment through systematic data collection on a number of key issues, the assumption is made that because NGO projects are designed to assist low income communities, both the projects and the participants will ipso facto illustrate how poor people are affected by adjustment, regardless of the reasons for establishing the project in the first place.

A second, and very different, methodological approach to the research problem was initiated in
October 1987 when the UNDP, the African Development Bank and the World Bank agreed to finance a project to assess the Social Dimensions of Structural Adjustment (SDA) in sub-Saharan Africa [UNDP 1987]. This was followed by the establishment of an SDA Project Unit within the World Bank, that has sought to establish the most appropriate means "to monitor the effects of Structural Adjustment and other policy lending programmes on the human dimension, particularly on the welfare of the poor'. Three draft volume documents, currently under discussion, have been concerned to identify the conceptual, empirical and policy frameworks for such a study. Amongst the package of research methods identified by this impressive undertaking is the Permanent Household Survey (PHS), a large scale structured household interview survey to be undertaken over a 5-7 year period, and intended as the basis for the collection of a comprehensive range of data on the socio-economic conditions on the country concerned.

A number of doubts about such an extensive and expensive exercise have been raised. Of particular relevance to the design of the Guayaquil research was the issue of time. Although the SDA project includes the parallel development of Social Action Programmes, for those concerned with the development of extensive compensatory and meso policies and programmes [Cornea et al. 1987], rather than social welfare handouts, the lengthy nature of the SDA project could cause frustration, since it is not yet clear when the first results will be available. Moreover, in an exercise dominated by professional macro-economists and statisticians, government civil servants and international and local consultants, there are concerns both over the process of defining the research hypotheses, as well as whether within the extensive, and therefore somewhat indiscriminate, data collection exercise it will be possible to trace the social consequences of SAP.

One particular criticism concerns the relative appropriateness of in-depth anthropological research techniques, rather than lengthy structured questionnaires focused primarily on the household as the unit of analysis, to adequately collect highly complex and sensitive information relating to the impact of such measures as changing food prices on both intrahousehold and inter-household decision-making and resource allocations. Finally, the SDA survey runs the danger of making two important assumptions which require vertification; firstly, it assumes that no useful existing data already exists; secondly in setting up teams of 'experts' to undertake such work, it assumes the absence of local personnel in low-income communities capable of participating in the research effort in any way other than as respondents affected by SAP. 
A third potential research methodology considered was that of rapid rural appraisal (RRA), particularly because it has been designed to achieve cost effective research in terms of time, and relevant and useful data. RRA emphasises the importance of taking advantage of available information, the knowledge and experience of local people, direct observation, key informants, the identification of use of key indicators, group interviews and the informal interview [Chambers 1985]. Structured questionnaire surveys are not seen as an appropriate or effective method of generating social information because of the quality of data obtained and the lengthy delays in the analysis and reporting of data. Indeed it is argued that 'often the most useful information comes not from the survey itself but from the observations (in fact, forms of RRA) by those who conduct it' [Chambers 1985:403].

However, while there are undoubtedly arguments in favour of limiting the role of questionnaire surveys in RRA, there are good reasons for their use in research addressing the social costs of SAP which suggest the need for reappraisal of the questionnaire issue. In the first instance, a body of data existed from a previous survey conducted in $1977 / 78$ which provided the basis for a comparative analysis if the same population was scientifically sampled. In the second instance it was considered necessary to undertake a household survey that could be analysed in the field in order to identify key issues for more qualitative anthropological research, but also to provide the basis for selective, representative households for a second stage in-depth semi-structured subsample. The challenge was to test out whether this might be undertaken rapidly within the available time.

\section{The Research Location}

The research was undertaken in the community of Indio Guayas, a low income area located in Guayaquil, the largest city and main port of Ecuador, a country beset by problems of debt and recession, and, since the early 1980s implementing SAP [World Bank 1984; World Bank 1988]. Indio Guayas was an area of tidal swampland settled in the early 1970s as a 'pioneer settlement' of young upwardly mobile families, who moved from city centre rental accommodation to acquire their own 10 by 30 metre plots, and de facto own their homes. During the late 1970 s and early 1980s the residents mobilised and petitioned local politicians and government to provide infill, drinking water and electricity [Moser 1982]. It is a heterogeneous community, with research in the late 1970 s and early 1980s revealing that far from being society's casualties the residents were aspiring through hard work and initiative to improve their standard of living, and, through better health and education, the employment prospects for their children, if not themselves [Moser 1981].
Indio Guayas was identified as the most suitable area for research not only because it had the necessary characteristics of a low income urban community in a country implementing SAP, but also because of the long-term close association between one of the researchers/authors and leaders and members of the community. This suggested a number of potential benefits for the implementation of the research. Contact with the leaders of Indio Guayas had begun in 1977-78 when long-term anthropological research on community settlement and consolidation was first undertaken. Subsequent research visits in 1982 and 1987 had strengthened a relationship based on long term reciprocity in which research results had been taken back into the community and used for their benefit.

The nature of the relationship with community leaders can have a significant bearing on the direction of the research. It is not only important to gain agreement from the community leadership over the objectives of the research, but it is also of paramount importance to seek advice as to how to get the community involved in the research project, and how the researchers themselves should get involved in the community. This means that leaders are identified not necessarily in terms of their status, but in terms of their knowledge of the community and their recognition as leaders by the community as a whole.

Because of the long term relationship it was possible for the authors to live in the community throughout the six week duration of the fieldwork, in sharp contrast to many researchers who tend to commute daily from the comfort of city centre hotels. Another critical factor, given that this is a community in which the leader had wide credibility, was that it meant the intentions of the research project could be very quickly communicated to the community at large, reducing to a minimum the common suspicion associated with data collection. This was accomplished within a few days of arrival at the first weekly community meeting which allowed us to be formally presented to the community; for us to explain the purpose of our research, and to allow the community leader to endorse publicly the research project and ask the community for their support and collaboration.

The Indio Guayas example is not a special case. A relationship of long term reciprocity can take different forms, all of which can be equally valid. For instance, an introduction to a community can be facilitated through an international $\mathrm{NGO}$, church or local groups, with a long term relationship based on development or welfare work. Indeed, precisely because of their long term contact and involvement with local leaders, development agencies like Oxfam, unlike official government researchers employed on the SDA survey for example, are in many respects in a better position to pursue research into social consequences of SAP on poor communities. 


\section{The Questionnaire Survey}

The decision to undertake a rapid questionnaire survey (referred to as the survey) was facilitated by a thorough knowledge of the research location and prior identification of the specific research topic. Before going into the field a draft questionnaire was designed with a range of questions relating to issues affected by changes in income and employment, in consumption patterns and in sectoral spending in education, health and public works. Questions relating to household composition and employment in the survey were more specific and detailed than those in the earlier household survey carried out in 1977-78. The survey was tightly structured to allow for comparisons to be made over the ten year period, but also open ended at the end to allow for supplementary questions on subjects of importance. With the clear identification of issues it is essential to prepare the questionnaire before fieldwork begins partly because it is easier to amend questions after the pilot than to prepare a questionnaire from scratch and because the focus of the questions is not likely to change [Croll 1984].

The advantages of living in Indio Guayas were immediately clear. It made it possible to pilot the survey at the same time as preparing for its implementation. During the day the community was mapped and each house located and given an address, while in the evening the draft questionnaire was revised with assistance from community leaders and a circle of friends. The validity of each question was discussed to crossback our a priori assumptions about its relevance with the experience of the community. The pilot process led both to amendments of some questions and to the discarding of others. This exercise proved to be the first phase in an interactive process that not only resulted in a revision of some of the research objectives but also reinforced the importance and relevance of the work to the community itself. In this way the work also quickly lost its 'academic' gloss, with areas of collaboration between the researchers and community further defined.

Four person days were required to elaborate an accurate map of the six blocks in the community which would act as the sampling frame from which the sample was selected. The six blocks corresponded to those surveyed previously in 1977/78 and covered areas that were consolidated with infill, water and electricity, and areas that still extended out on catwalks into the mangrove swamps. Two people working together quickened the mapping process since as one person read out the address, house type (materials used, size and number of storeys), the other noted the details on a working copy for transfer to a fair copy made later. On the spot decisions had to be made as to whether multi-storey buildings contained more than one residential unit. While all possible care was also taken to include only residential properties, some commercial properties were recorded in the sampling frame and there was duplication when on two occasions the same unit was included twice. In addition, the interviewing stage showed that in a small number of cases it had not been possible to locate houses which had been built at the back of the solar, or lot, and which remained hidden behind the street facing house but without a separate street access.

Not only did the map act as the frame from which to draw a 'tailor-made' sample of houses for interview but it also provided the control to ensure that only those selected for interview were interviewed. The accuracy of this procedure ensured that at the time of the second stage follow up semi-structured interviews (referred to as the sub-sample), all those selected were located without difficulty. It should be noted that the comparison of the 1988 map with the 1977-78 map also provided important insights into the extent of settlement expansion into the swamplands as well as community consolidation in terms of housing materials used and density of property.

The sample frame contained $46 \mathrm{l}$ units and it was possible to identify three equal-sized clusters of units, clearly defined by the time at which initial settlement began; two blocks were settled in the early 1970s, two in the mid-1970s and two in the late 1970s. It was decided to sample equally from each cluster and that the optimum size of the sample would be 164 . A simple random sample was chosen by using random number tables, rather than systematic selection based on a starting number chosen at random. The survey aimed to collect household level data and a simple provision was designed which used the number of the questionnaire to make the choice between two households when there was more than one in the same sampling unit.

Just over one week after arriving in Indio Guayas the revised survey was photocopied, collated and ready for use, and the random selection of 164 houses for interview had been made. In view of time contraints, and the research agenda, it was decided to use three local people as interviewers, making five in total, including the two authors. Those selected were all women who had completed secondary education and had experience as community level workers either as pre-school teachers or health promoters. It had been thought possible to use men interviewers but their work and study commitments were too inflexible. It later emerged that one interviewer had survey experience in a study of domestic violence undertaken by a local NGO and this experience together with her considerable ability as an interviewer in the local community meant she also participated in the subsample interviews described below. The choice of female interviewers was not crucial at this stage since 
the questions in the surveys aimed to collect data at the level of the household and were not gender specific.

One advantage of using local people was familiarity with the community, which meant that interviews were completed with households that otherwise would have not responded to the survey, providing one reason for the very low rejection rate of only 4 per cent. Although training was given both on the purpose and the practicalities of the questionnaire a great deal of supervision was nevertheless required. Each interviewer only completed up to five questionnaires at any one time. After each interviewing session a detailed check was made of the completed questionnaire in conjunction with the interviewer. This was the opportunity to ensure all the questions had been answered correctly as well as to check on additional points of information arising from each interview, such as the identification of potential interviewers for the next stage. In a small number of cases return visits were necessary in order to collect omitted data. Gradually, the time involved in checking each questionnaire decreased and improvements in interviewers' skills were clearly revealed in the quality and breadth of information collected as the days proceeded. The fact that the two authors also interviewed helped enormously since problem questions could be identified and advice given on how best to handle them; it was possible to report back on interesting interviews; and it meant that the completion of the survey became a shared task. This process showed us that with patience, training and close supervision it is possible to find good fieldworkers from the suburbios themselves, thus obviating the need to bring in so-called professionals (in Guayaquil these are often social work graduates) from outside the community.

The three interviewers also had other responsibilities in their roles as working women and mothers and it was necessary to recognise that domestic and productive activities took precedent over the immediate checking of completed questionnaires. This task was often left until later in the evenings. Such close monitoring and control over the interviewers was only feasible because we lived in the community and could gather every evening in the front room of one of the interviewers. This would have been inconceivable because of distance, transport and also the lack of familiarity if we had to commute daily from the city centre. Moreover, by remaining within walking distance of the survey area where the interviews were taking place, appointments were often fixed to do an interview at a mutually convenient time. This flexibility was also a factor contributing to a low rejection rate since some people were only available at a specific time. This was particularly the case with some of the poorest who worked very long hours and who were only available on Sundays or Saturday evenings. If we had lived in the city centre, such appointments would have been far more difficult to make, let alone keep.

The practice of checking questionnaires as they were completed provided the basis of a daily evening conference at which progress in terms of numbers of completed questionnaires was reviewed, and more importantly research results were monitored and discussed. An ongoing analysis allowed for the partial testing of the hypothesis, and the identification of important issues which required more in-depth inquiry. These were used to form the basis of the sub-sample.

The three local interviewers were paid for each completed questionnaire. A rate was fixed which took into account both minimum wage levels and prevailing rates paid in other questionnaire surveys. Payment avoided the problem apparent in other projects in the community where community labour, unlike professional labour, is not remunerated [Moser and Sollis 1989]. It also ensured that maximum energy was focused on the survey since the interviewers were prepared to be flexible and cope with the strains of the work over the short term. The pace of the survey was therefore crucial and towards the end of the third week in the suburbios the sample was completed, and all the possible interviews had been carried out. This interview phase of the research took eight days and resulted in a total of 141 completed questionnaires, seven rejections, six empty houses and 10 that were impossible to interview for diverse reasons.

\section{Comparative Surveys Analysis in the Field}

With the completed questionnaire preliminary analysis of the data was possible. This was done comparatively with the results of the 1977-78 survey over four main household variables - size, economically active structure, composition, and occupations. One of the most important comparative results related to changing employment patterns and their impact on household structures. Preliminary analysis of the data showed that neither men nor women's employment categories has changed significantly during this period [Moser 1989a] but that the decline in men's wage levels, and changes in work conditions (less secure waged work and increase in casual/day labouring) meant that fewer men were generating a reliable income than before, and the value of their wage packet was lower. This meant more women had to work in income generating activities in 1988 than was the case in 1978.

With changes in the number of economically active in the household, important questions for further enquiry were identified concerning household-level decisions regarding the division of labour within the household. It was recognised as important to plot this over the ten year period in order to identify, for 
instance, the extent to which daughters or sons replaced their mothers in undertaking reproductive/ domestic tasks to release their mothers for productive work. Additional questions were concerned with the implications of women's reduced time for reproductive activities on children's welfare, and on women's attitude to fertility. Another significant change identified was in the composition of households, especially an increase in the number of women headed households and a change in the formation of extended families. A second series of questions therefore emerged around the processes leading to de facto women headed households. A third set of questions was concerned with the reasons for the increase in extended families containing married sons and daughters and their income earning partners, attitudes towards such household structures and its implications in terms of division of labour.

\section{The Sub-sample}

The speed with which the first questionnaire was carried out meant there was sufficient time also to undertake a smaller second questionnaire, with a smaller number of households selected from the first sample. The purpose would be to deepen our understanding of issues that still remained unclear and to elaborate on the results that we obtained from the first survey. From the preliminary analysis of the survey data seven distinct household types were identified, which varied from nuclear family households to women headed households and several distinct types of extended family.

The sub-sample was weighted to those categories that would give insight into the issues outlined above, and focused on those which would provide representative examples as well as where sympathetic women respondents had been identified in the first survey. Women only were selected for the sub-sample because the issues relating to the impact of SAP had direct impact on them and because through their roles in the family they had the best knowledge of how families were affected by SAP. It was clear that there were some women who would be more reluctant to provide a second interview and this was an important consideration since collaboration was even more crucial the second time around because of the length of the questionnaire and the sensitive nature of the information required.

The preparation of the sub-sample required a degree of concentration and peace so it was done in a seaside hotel over a puente, or holiday weekend, away from the noise, bustle and heat of the suburbios. The analysis of the data, the writing of the questionnaire and the sample selection of 30 women to interview took four days to complete. From the questions included in the sub-sample questionnaire it was decided it was more appropriate for the female researcher to undertake the sub-sample interviews while the male researcher collected secondary material. The decision was also taken to use one of the three women who had participated in the first survey since she had proved an extremely able field worker. As far as possible continuity was looked for with the two interviewers returning to the women they interviewed first time round.

From the experience of implementing the sub-sample several important conclusions can be drawn. The fact that none of the women selected for interview refused to participate shows that it was possible, in certain circumstances, to conduct in-depth follow-up interviews on sensitive issues. The good response was greatly assisted by being able to return and ask for the respondent by name and through remembering all the necessary information from the first questionnaire to indicate the continuity between the first and second interview. Finally, the use of a life history methodology successfully used in previous fieldwork [Sollis 1978] helped to make the completion of the questionnaire a common objective for interviewer and respondent alike and focused attention away from the length of time taken to complete the interview.

\section{Secondary Data Collection}

It was recognised at the start of the research that secondary data both at the level of Indio Guayas and Guayaquil would be necessary in order to establish the contextual framework for analysis of the questionnaire data and provide the basis for establishing causal links between processes of impoverishment and SAP. Although it was possible to define certain areas prior to the implementation of the survey, the results obtained from this stage also suggested new material that was required. For example, the survey indicated that a significant number of households sent children to one of the number of private primary schools in, or in the vicinity of, Indio Guayas, despite the proximity of a large state primary school. It was therefore important to better understand through interviews with the school principal or owner, the nature of the service provided by private education and its role at a time when education budget cuts were affecting the quality of state education and when disposable incomes were affected by increased prices for basic goods. Similarly, the frequent use of private and charity health care rather than use of state run health centres led to data collection on the incidence of malnutrition from the files of a local charity clinic; the mapping of the community to show the growth of private health services - doctors, dentists, chemists and laboratories; the history of community participation in a UNICEF/Ministry of Public Health primary health care programme was documented from a community perspective [Moser and Sollis 
1989]; and in-depth interviews with the staff of state health centres.

The same process of analysis led to interviews of key informants in Indio Guayas on a variety of other subjects ranging from the practice of extending credit at the local corner shops; the workings of locally based savings and loans schemes and Christmas clubs; the role of evangelical protestant churches; and the incidence and context of drugs abuse. Additional information was also collected on the community development activities of an international child sponsorship NGO and the impact of its interventions in housing, health provision and education support.

Finally, the survey helped to focus the data needs at the level of Guayaquil. Education and health ministry archives were scoured for disaggregated information on mortality, incidence of malnutrition, school drop out rates, and other indices that would place Indio Guayas in the Guayaquil city context. However, for several reasons these searches were not always fruitful. August 1988 was a time of change of government and out-going officials were most interested in the handover to their successors. Sometimes, the disaggregated data for Guayaquil did not exist, but at other times the lack of interest shown by bureaucracy prevented any meaningful progress.

\section{Conclusions}

There are a number of conclusions that can be drawn from the fieldwork experience in Guayaquil. The first is the fact that in low income urban communities there are human resources, particularly women, with accumulated skills and knowledge that can be of use in social research. Moreover, if their work is valued correctly, the commitment of these human resources need not benefit the research work alone, leading to a successful research outcome, but can have a residual effect on the community itself. Guayaquil is by no means atypical in this respect; other urban centres in Latin America, as well as Africa and Asia, almost certainly contain educated underemployed men and women living in slum communities, who can provide an important contribution to the feasibility of rapid urban research.

The research also highlights the importance of the nature of the relationship with community leaders. This can have a significant impact both on the initial practicability of research into the social dimensions of SAP and its subsequent direction. However, the introduction to Indio Guayas community described in this paper is by no means unique; the work of other academics and researchers on communities should also be tapped by policy makers, likewise organisations, especially local and international NGOs, have access to communities on the basis of an identified reciprocity. Precisely because of their long term commitment to community development and welfare work, development agencies are in a favoured position to pursue investigation into the social dimensions of SAP on poor communities. To date, unfortunately such potential has not been sufficiently recognised, with an important opportunity missed for nongovernmental agencies and low-income communities alike.

In undertaking this research a gender division of data collection was recognised as essential. Clear areas of investigation were identified, where because of sensitivity of information it was more appropriate for the female researcher to speak to women and likewise for the male researcher to talk to men. In complex research areas where distinct types of information are required from different informants in order to obtain a clear picture of what is happening there, research teams with both men and women are an imperative.

Finally, this research has shown that it is possible to undertake rapid social surveys in urban areas, if the research framework is prepared in advance, with initial questions clearly identified. Moreover, the Guayaquil methodology also shows that a survey is not necessarily the end of the research, but simply the first stage in a research process which allows for further stages of data collection, utilising other methodological approaches, with on the spot analysis a built in component. The fact that the community was well known allowed for this methodology to develop. It may be the case that where researchers are less familiar with the community there may be the need to include additional stages in the data collection. This might include for example, in-depth work first in order to refine the hypotheses for more extensive testing by means of a survey. Nevertheless, whatever the methodology, the research process is far richer and more rewarding if shared with the subjects of the research, and, this as this article has shown, is best achieved by living and working in the community.

\section{References}

Chambers, R., 1985, 'Shortcut methods of gathering social information for rural development projects', in Putting People First: Sociological Variables in Rural Development, Michael Cernea (ed.), Washington, Oxford University Press/World Bank

Cornea, G., Jolly, R., and Stewart, F., 1987, Adjustment with a Human Face. Volume 1, Oxford, Oxford University Press

-1988, Adjustment with a Human Face. Volume 2, Oxford, Oxford University Press

Croll, E., 1984, 'Research methodologies appropriate to rapid appraisal: A Chinese Experience', in IDS Bulletin 15, $1: 51-57$

Clark, J., 1987, NGOs and Structural Adjustment, in United Nations Non-Government Liaison Service (Geneva), Occasional Paper No. 3 
- 1988, Debt and Poverty: A case study of Zambia, Oxford, Oxfam

Demery, L. and Addison, T., 1987, The Alleviation of Poverty under Structural Adjustment, Washington, World Bank

Elson, D., 1987, The impact of Structural Adjustment on women: Concepts and Issues, paper presented at the Institute of African Alternatives Conference, City University, London

Gluckman, M., 1958, Analysis of a social situation in Modern Zululand, Rhodes-Livingstone paper no 28, Manchester, Manchester University Press for the Rhodes-Livingstone Institute (now the Institute for African Studies, University of Zambia)

Moser, C. O. N., 1981, 'Surviving in the suburbios', IDS Bulletin 12,3:19-29

- 1982, 'A home of one's own: squatter housing strategy in Guayaquil, Ecuador', in A. Gilbert (ed.) with Hardoy, J. and Ramirez, R., Urbanization in Contemporary Latin America, Wiley, London

- 1989, 'Gender Planning in the Third World: Meeting Practical and Strategic Gender Needs', in World Develop- ment, vol 17:11 pp 1799-1825

-1989a, "The impact of recession and structural adjustment policies at the micro-level: low-income women and their households in Guayaquil, Ecuador', Women. Recession and Adjustment in the Third World, UNICEF, New York

-and P. J. Sollis, 1989, The UNICEF/MSP Primary health care programme, Guayaquil, Ecuador: Evaluation of the Cisne Dos project from a community perspective, report prepared for UNICEF, New York, mimeo

Sollis, P. J., 1978, Employment and Migration in small town Colombia: The case of San Gil, Santander, University of London Ph.D. Thesis

United Nations Development Programme, 1987, Regional Programme for Africa: Fourth Cycle. Assessment of Social Dimensions of Structural Adjustment in Sub-Saharan Africa, paper no $\mathrm{RAF} / 86 / 037 / \mathrm{A} / 01 / 42$

World Bank, 1984, Ecuador: An agenda for Recovery and Sustained Growth, World Bank, Washington

- 1988, Ecuador: Country economic memorandum, World Bank, Washington 